\title{
Molecular structure of the largemouth bass (Micropterus salmoides) Myf5 gene and its effect on skeletal muscle growth
}

\author{
Yuhan Guo · Junjie Bai · Ouqin Chang · Haihua Lao • \\ Xing Ye $\cdot$ Jianren Luo
}

Received: 9 June 2008/ Accepted: 12 August 2008/Published online: 28 August 2008

(c) The Author(s) 2008. This article is published with open access at Springerlink.com

\begin{abstract}
Myogenic Regulatory Factors (MRFs), a family of basic helix-loop-helix (bHLH) transcription factors, play important roles in regulating skeletal muscle development and growth. Myf5, the primary factor of MRFs, initiates myogenesis. Its expression pattern during somitomyogenesis in some fish has been revealed. To further study its effect on fish muscle during postembryonic growth, characterization and function analysis of myf5 cDNA were carried out in largemouth bass. The 1,093 bp cDNA sequence was identified by RT-PCR and $3^{\prime}$ RACE, then the ORF of Myf5 cDNA was cloned into the expression vector pcDNA3.1(-)/mycHisB. The recombinant plasmid pcDNA3.1(-)/mycHisB-Myf5 was injected into the dorsal muscle of tilapias. RT-PCR and histochemical results showed that the exogenous gene was transcribed and translated in vivo. Its effect on muscle growth focused on myofiber hypertrophy in white muscle 60 days post injection. This indicated that overexpression of Myf5 can promote myogenesis during the fish muscle postembryonic growth period.
\end{abstract}

Keywords Myf5 - Largemouth bass - Expression vector . Muscle growth

Y. Guo · J. Bai $(\bowtie) \cdot$ O. Chang $\cdot$ H. Lao $\cdot$ X. Ye $\cdot$ J. Luo Key Laboratory of Tropical \& Subtropical Fish Breeding \& Cultivation of Chinese Academy of Fisheries Sciences, Pearl River Fisheries Research Institute, CAFS, Guangzhou 510380, China

e-mail: jjbai@163.net

Y. Guo

College of Aqua-Life Science and Technology, Shanghai

Fisheries University, Shanghai 200090, China

\section{Introduction}

The cell fate of skeletal muscle precursor is determined by the expression of myogenic regulatory factors (MRFs) that include Myf5, MyoD, myogenin and MRF4. These nuclear proteins all contain a basic helix-loop-helix (bHLH) domain. By the bHLH domain, they can dimerize with E-proteins to form protein dimmers [1-4] and bind to the consensus DNA sequence (CANNTG) as an E-box to activate the transcription of muscle-specific genes, such as the muscle creatine kinase gene and myosin light chain gene [5-7]. MRFs are expressed specifically in muscle cells, and forced expression in other cell types could induce the muscle differentiation programs in these cells $[8,9]$.

$M y f 5$, as the first expressed MRF, plays an essential role in the specification and proliferation of myoblasts [10-12]. Human Myf5 was discovered in 1989, and found to be capable of converting mouse $10 \mathrm{~T} 1 / 2 \mathrm{C} 3 \mathrm{H}$ fibroblasts into myosin expressing myotubes [13]. Myf5 gene-knockout mice exhibited delayed development of the epaxial musculature and died from severe rib abnormalities, suggesting that Myf5 primarily regulates the epaxial musculature formation [14-17]. In fish, several MRFs have been cloned and their molecular mechanisms on muscle development and growth have been partially revealed. For example, $M y f 5$ expression patterns during simitomyogenesis have been uncovered in zebrafish [18], striped bass [19], flounder [20] and sea perch [21]. In morpholino-injected zebrafish embryos, abnormal muscle development and defective somite patterning have been observed, suggesting that Myf5 plays a similar role in zebrafish and mammals [22]. Its function on postembryonic muscle growth was only reported in rainbow trout. During rainbow trout postnatal development, the expression of MRFs were revealed to be correlated with the muscle growth pattern [23], but the concrete mechanism of the promotion of 
muscle fiber postembryonic growth is still unclear. Unlike mammals, most of fish skeletal muscles grow dramatically during the post-larval life, involving continuous myofiber hyperplasia and hypertrophy processes [24]. The proliferation of a population of myogenic progenitor cells (MPCs) showing varying degrees of commitment to terminal differentiation to myoblasts contribute to these two processes [25]. Thus, MRFs may also have an important role in regulating muscle formation and growth during the postnatal period in fish. Investigating the effect of Myf5 on postembryonic fish muscle growth will be an important part of the molecular basis of muscle development and growth.

Largemouth bass has become an important cultured commercial freshwater species in China, and is a good subject for the study of fish growth as it has rapid postnatal growth. Here we report the isolation and characterization of the largemouth bass Myf5 cDNA, and the effect of its overexpression on postembryonic muscle growth in fish.

\section{Materials and methods}

\section{Experimental fish}

Largemouth bass and Nile tilapia were obtained from Pearl River Fisheries Research Institute. Nile Tilapia, which also belong to Perciformes, were used as the experimental animals to evaluate the effect of largemouth bass Myf5 on muscle growth for its close relationship to largemouth bass, easier raising and handling, and fewer diseases usually occur when kept in captivity than largemouth bass itself. The total length of the Nile tilapia used in this study ranged from 10 to $14 \mathrm{~cm}$. The Nile tilapia during this period showed the high growth rate. These Nile tilapia which all came from the full-sibs family, were injected with plasmids and further cultured for two months under controlled conditions (temperature $24 \pm 1{ }^{\circ} \mathrm{C}$; photoperiod 14:10 light:dark). All the fish were anaesthetized before handling.

Isolation of largemouth bass Myf5 cDNA

Total RNA was extracted from the trunk muscle of the largemouth bass weighing $400 \mathrm{~g}$, using the SV Total RNA Isolation System (Promega). First-strand cDNA was synthesized using the TaKaRa RNA PCR Kit (AMV) Ver. 3.0 $(\mathrm{TaKaRa})$. Three primers were designed with reference to the known nucleotide sequences of Myf5 from fish such as zebrafish, carp, striped bass, flounder, and rainbow trout. The sense primer F1 used was located at the initiation codon and the nested sense primer F2 used was located at the downstream of F1; F1: ATGGA(T/C)GTCTTCTC(G/A/C)(A/C) CATCCC and F2: CGCCATCCAGTACATCGAGAG. The antisense primer used was R1: TCACAG(G/T)ACGTGG
TAGACGGG. The PCR was performed using F1 and oligo dT adaptor primer (in kit, including dT and M13 Primer M4): GTTTTCCCAGTCACGAC. The parameters were 28 cycles of $94^{\circ} \mathrm{C}$ for $30 \mathrm{~s}, 54^{\circ} \mathrm{C}$ for $30 \mathrm{~s}, 72^{\circ} \mathrm{C}$ for $1 \mathrm{~min}$, with an additional initial 3-min denaturation at $94^{\circ} \mathrm{C}$ and a 5-min final extension at $72^{\circ} \mathrm{C}$. Then the nested PCR was performed using F1 and R1. 3'RACE was conducted using F2 and the M13 Primer M4 (obtained from the kit) according to the parameters above. The PCR products were subsequently cloned into the pMD19 T-vector (TaKaRa) and sequenced. The two fragments were then spliced to obtain the ORF and the $3^{\prime} \mathrm{UTR}$.

Construction of the recombinant plasmid pcDNA3.1(-)/mycHisB-Myf5

Two primers were designed to modify the Myf5 open reading frame (ORF) of largemouth bass, including an extra ApaI and $\mathrm{XbaI}$ adapter respectively. The sense primer F3: ATAG GGCCCACCATGACGTCTTCTCACCATC, and antisense primer R2: AGATCTAGAAACAGGACGTGGTAGAC, were synthesized (Invitrogen). After PCR amplification with PfuDNA polymerase, the product was digested with ApaI and $\mathrm{XbaI}$, and cloned into the same sites of the pcDNA3.1 $(-) /$ mycHisB plasmid (Invitrogen) to generate the recombinant pcDNA3.1(-)/mycHisB-Myf5 expression plasmid which was driven by the cytomegalovirus promoter (CMV).

\section{Route of plasmid intramuscular injection}

Tilapia were anaesthetized using $100 \mathrm{mg} / \mathrm{l} \mathrm{MS-222} \mathrm{(Sigma)}$ to avoid the fish struggling and the resulting muscle contractions which lead to a decrease of DNA-expression in mice [26]. About $40 \mu \mathrm{g}$ pcDNA3.1(-)/mycHisB-Myf5 and pcDNA3.1(-)/mycHisB plasmid were dissolved in $100 \mu \mathrm{l}$ $0.75 \% \mathrm{NaCl}$ respectively. The recombinant plasmid was injected into the tilapia dorsal muscle at the fifth scale in the lateral line of the right side to a depth of 5-7 $\mathrm{mm}$ at an angle of $45^{\circ}$, and the same position of the opposite side with the same depth was injected using the non-recombinant plasmid as a control. $48 \mathrm{~h}$ post-injection, total RNA was extracted from the muscle at the injected place using Trizol (Invitrogen), then was digested by RNase-Free DNase (Promega) to confirm no plasmid in RNA sample. RT-PCR was then conducted to examine the locally transcription of the exogenous gene using the sense primer F4: GCCATCCATTACA TGAGAGTC located at nucleotide position 331 of the largemouth bass Myf5 ORF and the antisense primer R3: CCTCTTCTGAGATGAGTTTTTG located in the myc tag of the recombinant plasmids. On the eighth day postinjection, immunohistochemistry was used to examine the translation of the exogenous gene. The recombinant plasmid expresses the Myf5:mychis fused protein which can be detected with the Anti-His Tag mouse monoclonal antibody. 
The muscle of the injection position was cut transversely into $1 \times 1 \times 1 \mathrm{~cm}^{3}$ and sectioned using routine paraffin sectioning. The Anti-His Tag mouse Monoclonal Antibody (BOSTER, China) was used as the first antibody (diluted $1: 100$ in PBS). All steps were carried out according to the SABC (Strept-Avidin Biotin Complex) kit protocol (BOSTER, China); the diaminobenzidine (DAB) substrate kit (BOSTER, China) was used for visualization. Sections were then rinsed and lightly stained with hematoxylin.

Evaluation of myofiber diameter and density

Sixty days post-injection, three individual tilapias were analyzed. The muscles of the same injection places in two sides was transversely cut into $0.5 \times 0.5 \times 1 \mathrm{~cm}^{3}$ tissue small blocks and fixed with formalin for $24 \mathrm{~h}$, and then embedded in paraffin, sectioned and stained with hematoxylin/eosin. The same hemi-myotomes in experiment and control sections from the same position of the two sides were selected for the measurement of diameters and densities of the muscle fibers (fibers were assumed to be roughly cylindrical). In one section, consecutive five different microscope fields $(10 \times 10)$ from the outer myofiber layers to inner were photographed, and these five fields almost covered the hemi-myotome in the section. The five pictures were measured respectively, and added up to obtain the mean value of the myofiber diameter and density. More than 500 white muscle fibers were observed per fish. The red muscle fibers are a thin layer on the body surface, and the cell numbers are limited. Thus more than 150 red muscle fibers were analyzed. A Student's $t$-test was used to determine whether significant differences existed between the recombinant plasmid injection sites and the non-recombinant plasmid injection sites.

\section{Results}

Sequences of nucleotide and deduced amino acid of largemouth bass Myf5

The cDNA length of largemouth bass Myf5 was 1,093 bp and contained a 723 bp ORF with a 370 bp flanking region at the $3^{\prime}$-end (GenBank accession no. EU555403). The deduced amino acid sequence of largemouth bass Myf 5 revealed a 240 amino acid polypeptide that contained a bHLH domain located at amino acid positions 56-124 (Fig. 1). No signal peptide was found using the SignalP3.0 analysis software on line (http://www.cbs.dtu.dk/service/SignalP).
Fig. 1 Nucleotide and deduced amino acid sequences of largemouth bass $M y f 5$ cDNA.

The bHLH domain is underlined; THA polyadenylation signal ATTAAA is shown in dark

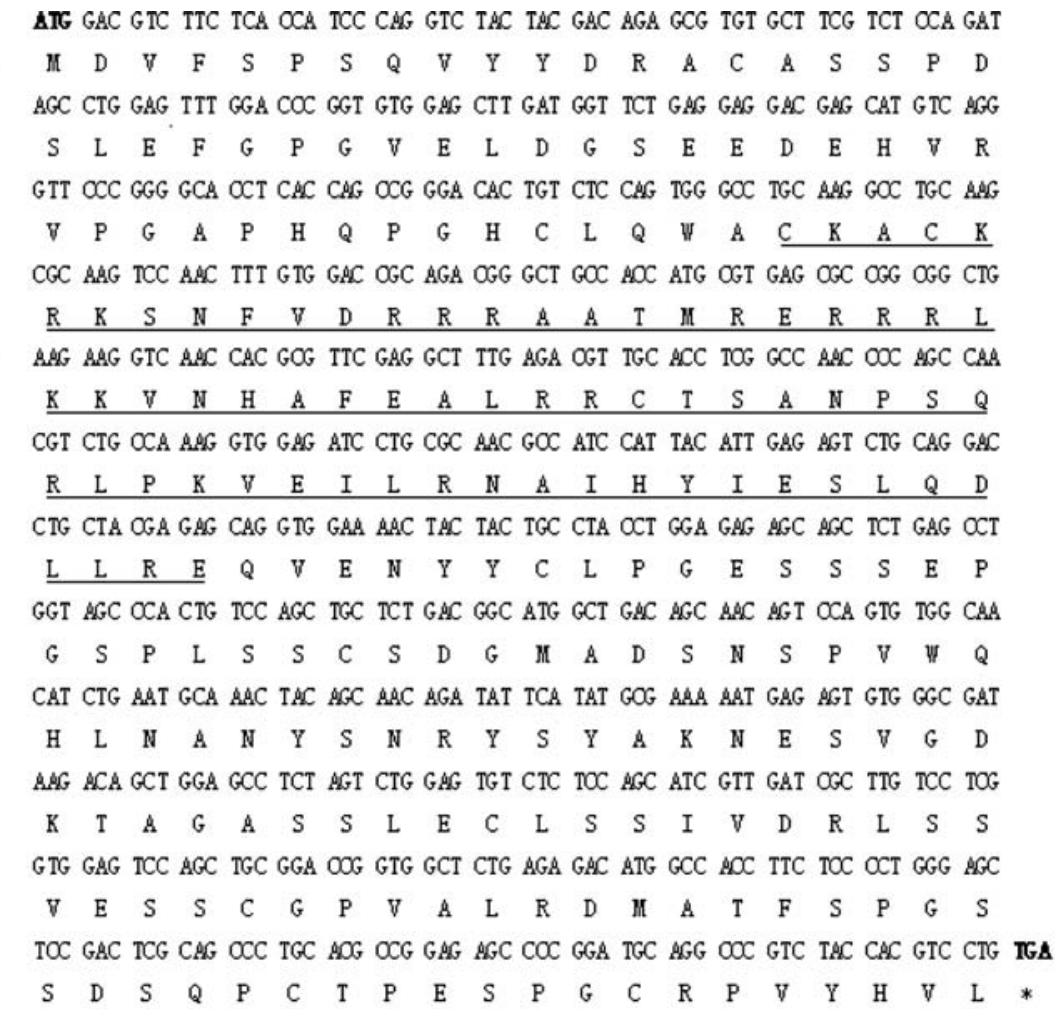


An alignment of the amino acid sequence of several Myf5 homologs reveals that the largemouth bass Myf5 shared higher identity with fish Myf5 than other vertebrate species (Fig. 2). For example, largemouth bass Myf5 exhibits 93\%, $92 \%, 92 \%, 82 \%, 76 \%$ and $75 \%$ identity with sea perch [21], striped bass [19], flounder [20], rainbow trout [27], carp [28] and zebrafish [18]; and 56\%, 56\%, 57\%, 57\% and 57\% identity with chicken [29], bovine [30], mice [31], humans [13], and the African clawed frog [32], respectively. The alignment results showed that Myf5 polypeptide sequences
Fig. 2 Comparison of the amino acid sequences and domains of the Myf5 protein among vertebrates. The sequence of the bHLH domain is underlined. The putative amino acid sequence of largemouth Myf5 (GenBank accession no. EU555403) is compared to the amino acid sequences of Stripped bass (Morone saxatilis, AF463525); Sea perch (Lateolabrax japonicus, DQ407725); Flounder (Paralichthys olivaceus, DQ872515); Zebrafish (Danio rerio, AF270789); Carp (Cyprinus carpio, AB012883); Atlantic salmon (Salmo salar, DQ452070); Rainbow trout (Oncorhynchus mykiss, AY751283); Fugu rubripes (Takifugu rubripes, AY445319); Pufferfish (Tetraodon nigroviridis, DQ453127); Human (Homo sapiens, X14894); Mouse (Mus musculus, NM_008656); Cow (Bos taurus, M95684); Chicken (Gallus gallus, X73250) and African clawed frog (Xenopus laevis, X56738). The alignment was generated using vector NTI 7.0 software. Identical and similar residues are shaded black and gray, respectively

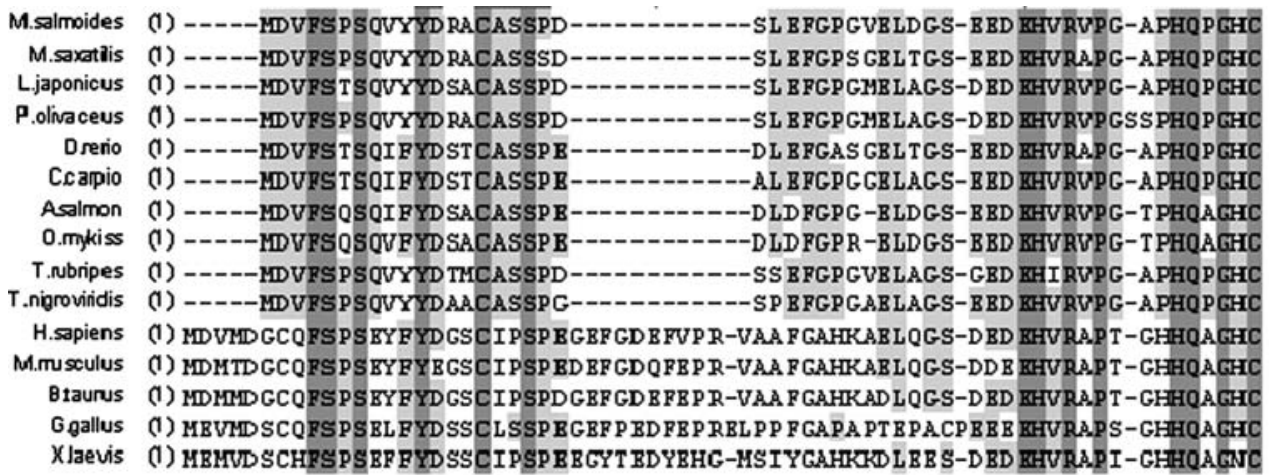

M.salmoides (52) LQUACKACKRKSNFVD RPRAA THRB RRRLKKVNHA PBAL RPCTSANPSOPL PKVBI L RNA IHY IBSLODL M.saxtlis (52) LQUACKACKRKSNFVD RPRAAT TMRB RPRLKLVVNHA PBAL RPC T SANPSQPL PKVBIL RNAIQYIBSLODI L.japonicus (52) LQUACKACKRKSNFVD RPRAA TMRBRPRLKKVNHA PBAL RPCTSANPSQPL PKVBIL RNAIOYIBSL ODL P.olinaceus (53) LQUACKACKRKSSFVD RPRAATMRB RPRLKKVNHA PBA RAC TSANPSORL PKVBI L RNA IHYIBSLQBI D reño (52) LQUACKACKRKASTVD RPRAATMRB RPRLKLVNHA PBAL RPCTSANPSQRL PKVBIL RNA IOY IBSLQBL C. aाpio (52) LQUACKACKRKASTUDRPRAA THRBRPRLKKUNHA PBAL RPCT SANPSQRL PKVBILRNAIQYIBSLOBL Asalmon (51) LQUACKACKRKSSTVD RPRAA THRB RPRL RKVNHGBBAL RPCT SANHSQPL PKVBI L RNA IQYIBSLQBL 0.mpiss (51) LQUACKACKRKSSTVD RPRAA TMRB RPRLKKVNHGPBAL RPC T SANPSQPL PKVBI L RNA IOYIBSLQBL T.nbripes (52) L PUACKACKRKSNFVD RPRAA THRB RPRLKIKUNHA FDAL RPCT SANSSQRL PKVBIL RNA IQYIBSLQBL

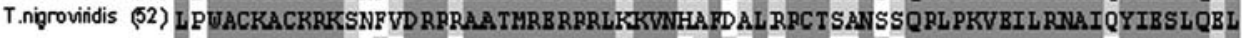
H.sapiens (88) LMUACKACKRKS TTMD RRKAA THRB RPRLKKVNQA PB T LKRCT T TNPNQRL PKVBI L RNA I RY IBSLQB L M.musculus (88) LMUACKACKRKSTTMD RPKAA TMRB RRRLKKVNQA PB T LKRC T T TNPNQRL PKVBI L RNA I RY IBS LQBL 8 taUrus (88) LMUACKACKRKS TTMD RPKAA THRB RPRLKLVNQA BD T LKPCT T TN PNQPL PKVBI L RNA IRY IBS LQBI

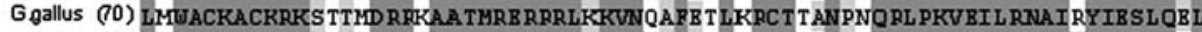
X Jaevis (88) LMUACKACKRKSST TDRPKAA TMRB RPRLKKVNQA BB TLKPCT T TNPNQRL PKVBIL RNA IOYIBSLODL

M.salmoides(122) L RBQUBNYYCLPGBSSSBPGSP LSSCSD GMADSNS PV-שQHLNANYSN R------YSYAKNBSVGDKTAG M.saxtlis (122) L HBQVBNYYGL PGBSSSBPGSP LSSCSD GHVDSNS PV-UQQLNANYSNS------YSYAKN-VCAISTVG L.japonicus (122) L RBQVBNYYCL P GBSSSBP GSP LSSCSD GMTDSNSSL-UQQLNANYGN S------YSYAKINDGLGDKAPG

P.olinaceus (123) L RBQVBNYYGL PGBSSS BPGSP LSSCSD GMADSNSPV-UHQLNANYSS S------YSYAKND--SDKAIC D renio (122) L RBQVBQYYSL PMBSSSBPASP SSSCSBSHVDCNS PV-WPQMNQNYGN S-----YNRDAONASTHBRTPG Cc arpio (122) L RB QVBNYYS L PMBSSSBPASP SSSC BSMVDCNS PV-UPOMN PNF GNN-----YNF BAQNASAVDRTPG Acalmon (121) L HBHVBNYYCL PGBSSS BP CSP SSSRSD SHUDCNI PVUTPQNNT SYGNN------YSY TRNUSSGBRGAG

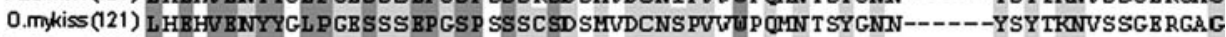
T.ubripes (122) L RBQVB SYYGL P GBSGS BP GSP LSNCSD GP ADSNS PV-WQQMNAVYSS G------YLYAKNBILTDKTAC T.nigrovinidis (122) L RBQVBSYYGL PGBSGSBPGSP LSNCSDSAPDGSSPG-URQHS AAYGG GGGGGGGYPYAKNBI PAD RSAG H.sapiens (138) L RB QV BNYYSL P GQ SCS BP T SP TSNCSD GMP BCNS PV-US RKS STFD S IY-----CPDUSNVYATDKN-S M.musculus (138) L RBQVBNYYSLPGQSCS BP T SP TSNCSD GMP BCNSPV-USRKNSSRDS IY-----CPDVSNACAADKS-S Btauns (138) L RBQVBNYYS L PGQSCS BP T S P TSSCSD GMP ECNS PI-US RKS SSFDSVY-----CPDUPNVYATDKS-S G gallus (140) L RBQVBNYYHL PGQSCSBPT SP SSSCSDVHADSRS PV- PARGSSF BA GY-----CRBMPHGYAT BQSGA X Jaevis(138) L RBQUBNYYSL PGQSCT BPGSP MSSCSDGMSDCSSPQ-匹SGRNSSFDNVY-----CSDLQT SFSSTKL-T

M.salmoides(185) ASSLECLSS IVDRLSSVES-SCGPVALRDKATF SPGSSD-SQPCTPESPGCRPVYHVL M.sexatĭs(184) ASSL ECLSS IVDRLSSVES-SCGP ג ALRDTATFSPGSSD-SQPCTPESPGSRPVYHVL L japonicus(185) ASSLECLSS IVDRLSSVES-SCGP A ALRDKATFSPGSSD-SQPCTPESPGTRPVYHVL P.olivaceus(184) ASSLQCLSS IVDRLSSVES-SCGP A ALRDKATFSPGSTD-SQPCTPESPGARPVYHVL D.rento(186) VSSLQCLSS IVDRLSSVDP-----AGIRNKVVLSPTGSD-SQSSSPDSPNNRPVYHVL C.corpio (186) ASSLQCLSS IVDRLSSVDTG--VAMGIRNIVALSPTGSD-SQCSSADSPSNRPVYHVL A saimon(185) ASSL ARLSN IVDRLSSVD--ASAPAGLRDKL TFSPSSTD-SQPCTTESPGTRPVYHVL O.mykiss(185) ASSL גCLSS IVDRLSSVD--גS AP גGLRDKL TFSPSSTD-SQPCTPESPGTRPVYHVL T. nubripes(185) ASSLECLSS IVDRLSSVES-SCGP A ALRD AATF SPGS AE-SQPCTPESPGSRPVYHVL $T$ rigrovindis(191) ASSLECLSS IVDRLSSGES-GCGP AGPRD ASTFSPGSTE-SQPCTPESPGSRPVYHVL H.sapiens(201) LSSLDCLSN IVDR ITSSEQ---PGL PLQDL ASLSPVASTDSQPRTPGASSSRL IYHVL M musculus(201) VSSLDCLSS IVDRITSTEP---SELALQDTASLSPATSANSQP ATPGPSSSRL I YHVL B.taurus(201) LSSL D CLSS IVDRITNSEQ---PGL PLQDP ASL SPVASTDSQP ATPGASSSRL IYHVL G.gallus(204) LSSLDCLSS IVDRLSP AEE---PGL PLRHAGSLSPG ASIDSGPGTPGSPPPRRTYQAL $X$ laevis(201) LSSLDCLSSIVDRISSPQQ---CSLP IPDS ITPSP TSSTDSLPRSPD AHDCRP IYHVL 
of largemouth bass, sea perch and striped bass, which all belong to Perciformes, are highly conserved.

Identification of the recombinant plasmid pcDNA3.1(-)/ mycHisB-Myf5 for the intramuscular injection

When the 6,156-bp constructed recombinant plasmid was double-digested with ApaI and XbaI, a 729 bp DNA fragment was obtained as expected. Sequencing results revealed that the ORF was complete and correct.

RT-PCR result to confirm transcription of the exogenous gene

The recombinant plasmid pcDNA3.1(-)/mycHisB-Myf5 and non-recombinant plasmid pcDNA3.1(-)/mycHisB were injected into trunk muscle of Nile Tilapia. RT-PCR was used to detect the transcription of the exogenous gene. The right side of the tilapia dorsal muscle injected with the pcDNA3.1(-)/mycHisB-Myf5 plasmid was selected as the experimental group, and the same position of the opposite side of the fish that was injected with the pcDNA3.1(-)/ mycHisB plasmid was used as the control. On the third day post-injection, RT-PCR was used to examine the exogenous gene transcription with using the sense primer located in the largemouth bass Myf5 ORF and the antisense primer located in the myc tag of the recombinant plasmid. The results demonstrated that the experimental side of the fish where the pcDNA3.1(-)/mycHisB-Myf5 plasmid had been injected showed myf5mycHis expression, while no transcription was detected in the control side (Fig. 3).

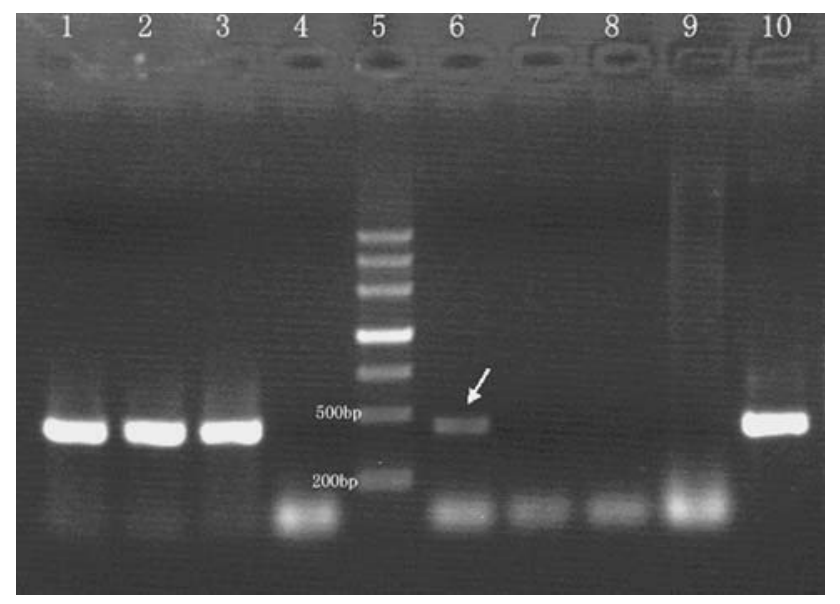

Fig. 3 RT-PCR to examine myf5mycHis transcription in vivo. Lane 1: beta-actin from the experimental side of the injected fish. Lane 2: beta-actin from the control side of the injected fish. Lane 3: beta-actin from non-injected fish. Lane 4: blank control. Lane 5: MarkerIII. Lane 6: myf5-mycHis from the experimental side of the injected fish. Lane 7: myf5-mycHis from the control side of the injected fish. Lane 8: myf5-mycHis from non-injected fish. Lane 9: blank control. Lane 10: the positive myf5-mycHis control (421 bp)
Immunohistochemistry results to confirm translation of the exogenous gene

Expression of myf5mycHis was confirmed by immunohistochemical staining of the transfected muscle 7 days after injection. The Anti-His Tag mouse Monoclonal Antibody (BOSTER, China) was used as the first antibody and the Biotin-Goat anti-mouse IgG (BOSTER, China) was used as the second antibody. Immunohistochemical sections of tilapia muscle are shown in Fig. 4. The transfected muscle cells were strongly stained around the injection site in the experimental side, but not stained on the control side.

Evaluations of muscle fiber change

Sixty days post-injection, the muscle around the injection position from the three individual tilapias were fixed with formalin for $24 \mathrm{~h}$ followed by routine paraffin sectioning

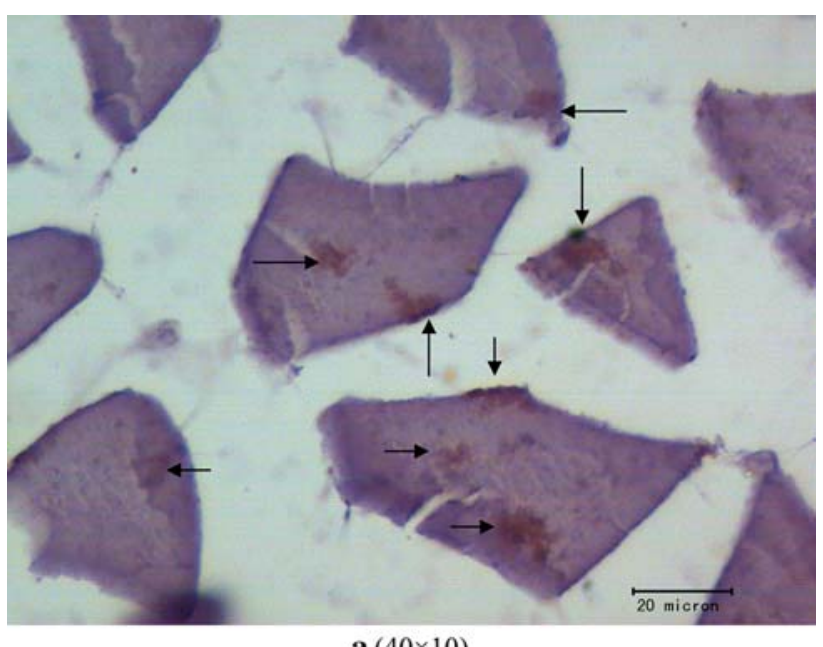

a $(40 \times 10)$

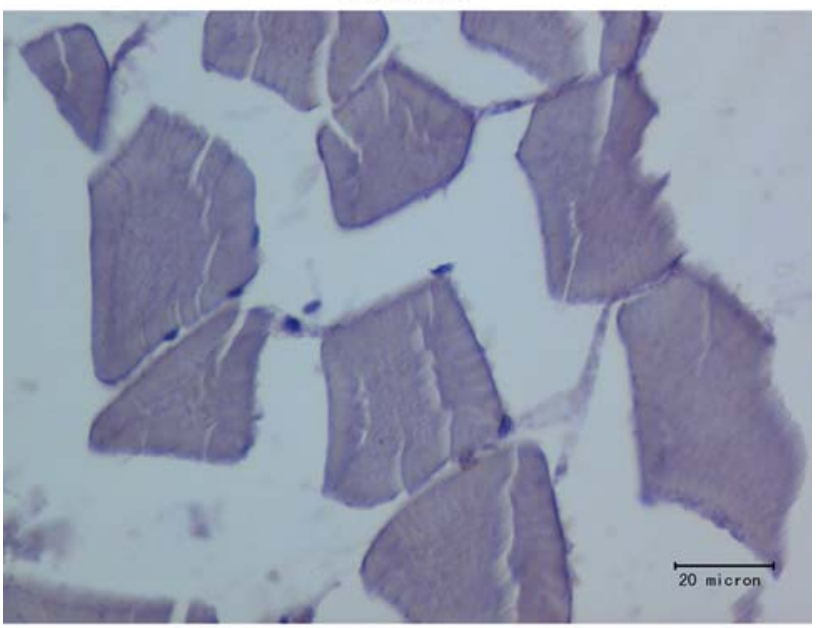

b $(40 \times 10)$

Fig. 4 Detection of myf5mycHis expression in vivo by immunohistochemistry. (a) The positive sample, the fusion protein expressed has been stained as shown by the brown spots, as the arrows indicate and (b) the control sample 
and hematoxylin/eosin staining (Fig. 5). The myofiber diameters of white and red muscle were evaluated respectively from the two sides of each tilapia (Table 1). The white muscle fiber diameters of fish 1,2 , and 3 increased $10 \%(5.2 \mu \mathrm{m}), 9 \%(4.5 \mu \mathrm{m})$ and $7 \%(3.5 \mu \mathrm{m})$ respectively compared with the control side; the average increase was $9 \%$. The size of the red fibers, however, had no significant changes $(P>0.05)$.

\section{Discussions}

Polypeptide structure analysis

The bHLH domain is present in some transcriptional regulators and is involved in DNA binding and protein dimerization. This domain of largemouth bass Myf5 is exactly identical to that of other vertebrates and exhibits
Fig. 5 Muscular paraffin sections of experimental and control injection sides in fish 1 $(10 \times 10)$, and the percentage of myofiber cells with different diameters shown in the histogram
Table 1 Myofiber diameter statistical analysis on day 60 post-injection

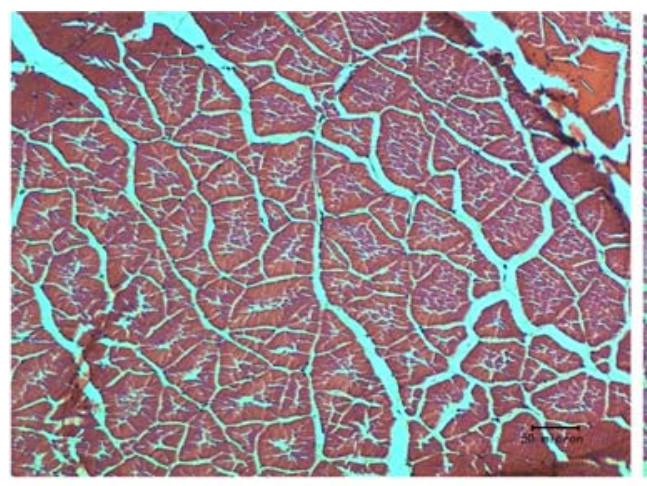

Control $(10 \times 10)$

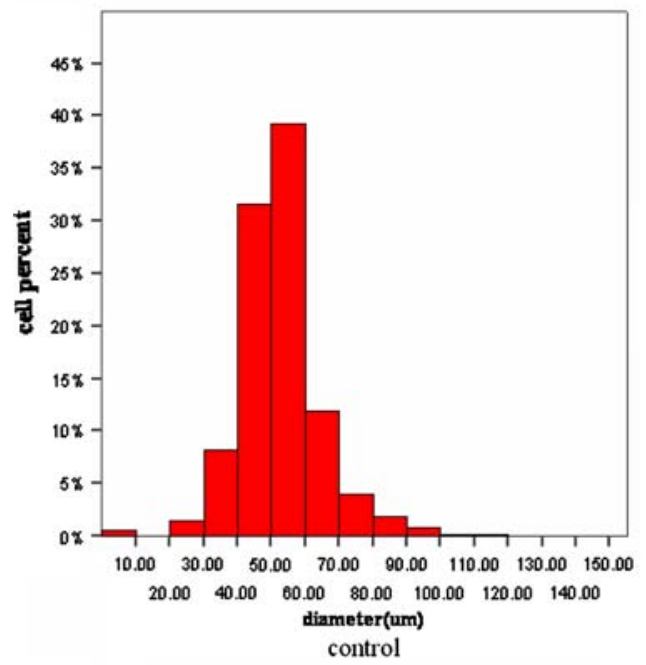

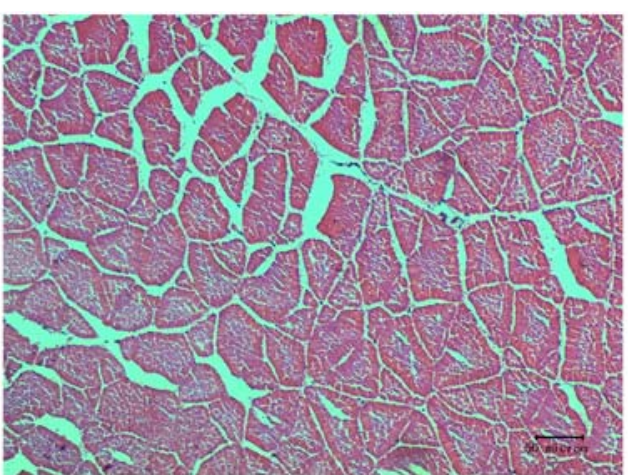

Experiment $(10 \times 10)$

fish 1

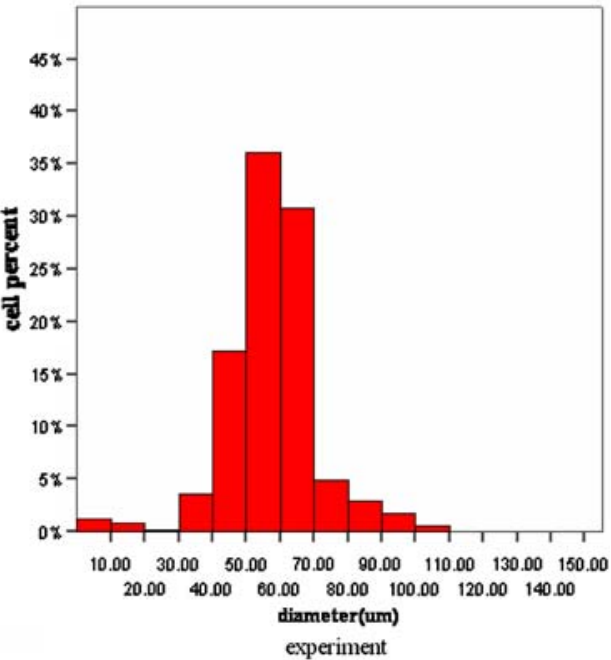

\begin{tabular}{|c|c|c|c|c|}
\hline & \multicolumn{2}{|c|}{ White muscle fiber diameter $(\mu \mathrm{m})$} & \multicolumn{2}{|c|}{ Red muscle fiber diameter $(\mu \mathrm{m})$} \\
\hline & Experiment & Control & Experiment & Control \\
\hline \multirow[t]{3}{*}{ Fish 1} & $57.5 \pm 18.6$ & $52.7 \pm 12.1$ & $39.7 \pm 11.3$ & $38.5 \pm 8.0$ \\
\hline & $N=512$ & $N=528$ & $N=264$ & $N=232$ \\
\hline & \multicolumn{2}{|c|}{$P<0.01$} & \multicolumn{2}{|c|}{$P>0.05$} \\
\hline \multirow[t]{3}{*}{ Fish 2} & $54.1 \pm 14.8$ & $49.6 \pm 12.3$ & $29.6 \pm 8.3$ & $30.0 \pm 8.4$ \\
\hline & $N=574$ & $N=589$ & $N=236$ & $N=241$ \\
\hline & \multicolumn{2}{|c|}{$P<0.01$} & \multicolumn{2}{|c|}{$P>0.05$} \\
\hline \multirow[t]{3}{*}{ Fish 3} & $56.7 \pm 16.4$ & $53.2 \pm 17.1$ & $35.2 \pm 9.2$ & $36.8 \pm 8.7$ \\
\hline & $N=551$ & $N=557$ & $N=157$ & $N=163$ \\
\hline & \multicolumn{2}{|c|}{$P<0.01$} & \multicolumn{2}{|c|}{$P>0.05$} \\
\hline
\end{tabular}


$99 \%, 97 \%, 93 \%, 84 \%$ and $84 \%$ identity with sea perch, striped bass, zebrafish, mice and humans, suggesting that largemouth bass Myf5 probably acts as a transcriptional factor to regulate muscle-specific genes, as its homologs do in other species.

The effect of exogenous Myf5 on fish muscle fiber size and density

Considered with the difficulty in the culture of fish muscle cells and satellite cells, we tried the intramuscular injection of plasmid pcDNA3.1(-)/mycHisB-Myf5 to study the effect of Myf5 on fish muscle growth rather than the transient transfection of foreign gene Myf5 into muscle cells. This strategy was demonstrated available by the RT-PCR and immunohistochemistry results.

Fish postembryonic muscle growth is different from mammals. In mammals, the number of muscle fibers is determined at birth, and muscle fibers only increase in diameter after birth [33]. The muscle fibers absorb additional nuclei derived from the proliferation of so-called satellite cells located between the basal lamina and sarcolemma [34]. In fish, however, postnatal muscle growth is characterized by continuous myofiber hyperplasia and hypertrophy [24]. Fish myogenic progenitor cells (MPCs), responsible for the postembryonic growth in teleosts, are analogous to satellite cells in mammals, but not exactly the same as they are not always located beneath the basal lamina of muscle fibers $[35,36]$. The model describing the main events of myogenesis in teleost skeletal muscle is that the pluripotent stem cells are specified to become myogenic progenitor cells (MPCs), and MPC progeny undergo a proliferation phase, and ultimately differentiate into myoblasts which have two cellular fates [25]. First, myoblasts can fuse into short myotubes that can be extended through the absorption of additional myoblasts to form new myofibers. Second, if the myoblasts were absorbed directly by existing fibers, the fiber-myoblast fusion can result in hypertrophy of the fibers [25]. In our experiment, the effect of Myf5 overexpression mainly focused on muscle fiber hypertrophy and the myofiber diameter was found to increase by $9 \%$ on average. Myofiber density, however, did not increase as expected and instead, all decreased (data not shown), suggesting that Myf5 may be responsible for the hypertrophy of muscle fiber predominantly during the post-larval period of fish. There is a restriction to the methodology used, however, in that an increase in the cross-section area of myofibers can result in a decrease in the number of myofibers fixed in a microscope field. The effect of myf5 on the process of muscle hyperplasia during the fish postnatal period needs to be further investigated. In our experiment, no significant changes were found for the red fibers. A determination for whether or not MPCs in red muscle have a different signal regulating pathway during fish postnatal muscle growth is worthy of further study.

In any case, it is likely that overexpression of exogenous Myf5 activated the differentiation of quiescent MPCs into myoblasts, myoblasts fused into the adjacent fibers and ultimately might lead to the hypertrophy of the existed fiber. In conclusion, this study indicated that the exogenous Myf5 probably promoted myogenesis during the postembryonic muscle growth period in fish.

Acknowledgments The authors wish to thank Dr. Yongjiang Ma and postgraduate Fengmei Wei from the South China Agriculture University for helping with the evaluation of muscle fiber diameter and density.

Open Access This article is distributed under the terms of the Creative Commons Attribution Noncommercial License which permits any noncommercial use, distribution, and reproduction in any medium, provided the original author(s) and source are credited.

\section{References}

1. Murre C, McCaw PS, Baltimore D (1989) A new binding and dimerization motif in immunoglobulin enhancer binding, daughterless, MyoD, and myc proteins. Cell 56:777-783. doi: 10.1016/0092-8674(89)90682-X

2. Sun XH, Baltimore D (1991) An inhibitory domain of E12 transcription factor prevents DNA binding in E12 homodimers but not in E12 heterodimers. Cell 64:459-470. doi:10.1016/ 0092-8674(91)90653-G

3. Lin H, Konieczny SF (1992) Identification of MRF4, myogenin, and E12 oligomer complexes by chemical crosslinking and twodimensional gel electrophoresis. J Biol Chem 267:4773-4780

4. Langlands K, Yin X, Anandi G, Prochownik EV (1997) Differential interactions of Id proteins with basic helix loop helix transcription factors. J Biol Chem 272:19785-19793. doi: 10.1074/jbc.272.32.19785

5. Jaynes JB, Johnson JE, Buskin JN, Gartside CL, Hauschka SD (1988) The muscle creatine kinase gene is regulated by multiple upstream elements, including a muscle-specific enhancer. Mol Cell Biol 8:62-70

6. Braun T, Arnold HH (1991) The four human muscle regulatory helix-loop-helix proteins Myf3-Myf6 exhibit similar heterodimerization and DNA binding properties. Nucleic Acids Res 19:5645-5651. doi:10.1093/nar/19.20.5645

7. Faerman A, Shani M (1993) The expression of the regulatory myosin light chain 2 gene during mouse embryogenesis. Development 118:919-929

8. Weintraub H, Tapscott SJ, Davis RL, Thayer ML, Adam MA, Lassar AB et al (1989) Activation of muscle specific genes in pigment, nerve, fat, liver, and fiberoblast cell lines by forced expression of MyoD. Proc Natl Acad Sci USA 86:5434-5438. doi:10.1073/pnas.86.14.5434

9. Weintraub H (1993) The MyoD family and myogenesis: redundancy, networks, and thresholds. Cell 75:1241-1244. doi:10.1016/ 0092-8674(93)90610-3

10. Rudnicki MA, Schnegelsberg PN, Stead RH, Braun T, Arnold HH, Jaenisch R (1993) MyoD or Myf-5 is required for the formation of skeletal muscle. Cell 75:1351-1359. doi:10.1016/0092-8674(93) 90621-V

11. Tajbakhsh S, Rocancourt D, Buckingham M (1996) Muscle progenitor cells failing to respond to positional cues adopt 
non-myogenic fates in myf-5 null mice. Nature 384:266-270. doi: $10.1038 / 384266 \mathrm{a} 0$

12. Kanellos T, Sylvester ID, Howarda CR, Russell PH (1999) DNA is as effective as protein at inducing antibody in fish. Vaccine 17:965-972. doi:10.1016/S0264-410X(98)00312-0

13. Braun T, Buschhausen-Denker G, Bober E, Tannich E, Arnold HH (1989) A novel human muscle factor related to but distinct from $M y o D 1$ induces myogenic conversion in 10T1/2 fibroblasts. EMBO J 8:701-709

14. Braun T, Rudnicki MA, Arnold HH, Jaenisch R (1992) Targeted inactivation of the mouse regulatory gene $M y f 5$ results in abnormal distal rib development and early postnatal death in homozygous mouse mutants. Cell 71:369-382. doi:10.1016/ 0092-8674(92)90507-9

15. Braun T, Bober E, Rudnicki MA, Jaenisch R, Arnold HH (1994) MyoD expression marks the onset of skeletal myogenesis in homozygous Myf5 mutant mice. Development 120:3083-3092

16. Kablar B, Krastel K, Ying C, Asakura A, Tapscott SJ, Rudnicki MA (1997) MyoD and Myf-5 differentially regulate the development of limb versus trunk skeletal muscle. Development $124: 4729-4738$

17. Kablar B, Krastel K, Tajbakhsh S, Rudnicki MA (2003) Myf5 and MyoD activation define independent myogenic compartments during embryonic development. Dev Biol 258:307-318. doi:10.1016/S0012-1606(03)00139-8

18. Chen YH, Lee WC, Liu CF, Tsai HJ (2001) Molecular structure, dynamic expression, and promoter analysis of zebrafish (Danio rerio) myf-5 gene. Genesis 29:22-35. doi :10.1002/1526-968X (200101)29:<22::AID-GENE1002>3.0.CO;2-Z

19. Tan X, Hoang L, Du SJ (2002) Characterization of muscle-regulatory genes, Myf5 and Myogenin, from striped bass and promoter analysis of muscle specific expression. Mar Biotechnol (NY) 4:537-545. doi:10.1007/s10126-002-0013-1

20. Tan X, Zhang Y, Zhang PJ, Xu P, Xu Y (2006) Molecular structure and expression patterns of flounder (Paralichthys olivaceus) Myf-5, a myogenic regulatory factor. Comp Biochem Physiol B 145:204-213. doi:10.1016/j.cbpb.2006.07.008

21. Ye HQ, Chen SL, Xu JY (2007) Molecular cloning and characterization of the Myf5 gene in sea perch (Lateolabrax japonicus). Comp Biochem Physiol B 147:452-459. doi:10.1016/j.cbpb. 2007.02.008

22. Chen YH, Tsai HJ (2002) Treatment with Myf5-morpholino results in somite patterning and brain formation defects in zebrafish. Differentiation 70:447-456. doi:10.1046/j.1432-0436. 2002.700807.x

23. Johansen KA, Overturf K (2005) Quantitative expression analysis of genes affecting muscle growth during development of rainbow trout (Oncorhynchus mykiss). Mar Biotechnol (NY) 7(6):576587. doi:10.1007/s10126-004-5133-3
24. Rowlerson A, Veggetti A (2001) Cellular mechanisms of postembryonic muscle growth in aquaculture species. In: Johnston IA (ed) Muscle growth and development, fish physiology, vol 18. Academic Press, London, pp 103-140

25. Johnston IA (2006) Environment and plasticity of myogenesis in teleost fish. Exp Biol 209:2249-2264. doi:10.1242/jeb.02153

26. Wells DJ (1995) Gene transfer by intramuscular injection of plasmid DNA. In: Dickson G (ed) Molecular and cell biology of human gene therapeutics. Chapman \& Hall, London, pp 83-103

27. Johansen KA, Overturf K (2005) Sequence, conservation, and quantitative expression of rainbow trout Myf5. Comp Biochem Physiol B 140:533-541. doi:10.1016/j.cbpc.2004.11.016

28. Kobiyama A, Nihei Y, Hirayama Y, Kikuchi K, Suetake H, Johnston IA et al (1998) Molecular cloning and developmental expression patterns of the MyoD and MEF2 families of muscle transcription factors in the carp. J Exp Biol 201:2801-2813

29. Saitoh O, Fujisawa-Sehara A, Nabeshima Y, Periasamy M (1993) Expression of myogenic factors in denervated chicken breast muscle: isolation of the chicken Myf5 gene. Nucleic Acids Res 21:2503-2509. doi:10.1093/nar/21.10.2503

30. Barth JL, Worrell RA, Crawford JM, Morris J, Ivarie R (1993) Isolation, sequence, and characterization of the bovine myogenic factor encoding gene myf-5. Gene 127:185-191. doi:10.1016/ 0378-1119(93)90717-H

31. Buonanno A, Apone L, Morasso MI, Beers R, Brenner HR, Eftimie R (1992) The MyoD family of myogenic factors is regulated by electrical activity: isolation and characterization of a mouse Myf-5 cDNA. Nucleic Acids Res 20:539-544. doi: $10.1093 /$ nar/20.3.539

32. Hopwood ND, Pluck A, Gurdon JB (1991) Xenopus Myf-5 marks early muscle cells and can activate muscle genes ectopically in early embryos. Development 111:551-560

33. Parker MH, Seale P, Rudnicki MA (2003) Looking back to the embryo: defining transcriptional networks in adult myogenesis. Nat Rev Genet 4:497-507. doi:10.1038/nrg1109

34. Bischoff R (1994) The satellite cell and muscle regeneration. In: Engel AG, Franszini-Armstrong C (eds) Myogenesis, vol 2. McGraw-Hill, New York, pp 97-118

35. Veggetti A, Mascarello F, Scapolo PA, Rowlerson A (1990) Hyperplastic and hypertrophic growth of lateral muscle in $D i$ centrachus labrax L. An ultrastructural and morphometric study. Anat Embryol (Berl) 182:1-10. doi:10.1007/BF00187522

36. Johnston IA, Manthri S, Alderson R, Smart A, Campbell P, Nickell D et al (2003) Fresh water environment affects growth rate and muscle fibre recruitment in seawater stages of Atlantic salmon (Salmo salar L.). J Exp Biol 206:1337-1351. doi: $10.1242 /$ jeb.00262 